\title{
ECONOMIC OSCILLATIONS WITH ENDOGENOUS \\ POPULATION, HUMAN CAPITAL AND WEALTH
}

Wei-Bin ZHANG, Prof. PhD

Ritsumeikan Asia Pacific University, Japan

E-mail: wbz1@apu.ac.jp

\begin{abstract}
This paper demonstrates oscillations in the economic growth model with endogenous population growth and physical and human capital accumulation proposed by Zhang (2014). This study generalizes Zhang's model by treating all the time-independent parameters as time-dependent parameters. The model is a synthesis of the Solow growth model, Uzawa-Lucas two-sector model, and the Haavelmo population model and the Barro-Becker fertility choice model. The model studies the dynamic interdependence between population change, wealth accumulation, and human capital accumulation. We simulate the model to demonstrate existence of business cycles under different periodic shocks.
\end{abstract}

Keywords: economic oscillations; propensity to have children; human capital; endogenous population

JEL Classification: $\mathrm{E}_{24}, \mathrm{O}_{47}$

\section{Introduction}

Modern economies are characterized of volatile changes in association with fast capital accumulation, widely spread education and fast accumulated human capital, and population dynamics. In many parts of the world life expectancy has increased dramatically. To explain the economic mechanisms and dynamic phenomena of these changes, this study builds a dynamic model to study interactions between wealth accumulation, human capital accumulation, and population dynamics with endogenous birth rate and mortality rate. This study is mainly concerned with demonstrating economic fluctuations under different exogenous shocks. There are a lot of theoretical and empirical research about mechanisms and phenomena of economic fluctuations. (Lucas, 1977; Zhang, 1991, 2005, 2006; Chatterjee and Ravikumar, 1992; Gabaix, 2011; Giovanni, et al. 2014; Stella, 2015). Nevertheless, there are only a few theoretical models which identify fluctuations due to dynamic interdependence between economic growth, human capital accumulation and population change. This study attempts to identify economic fluctuations.

The model by Zhang (2014) is based on some well-known models in the literature of economic growth and population dynamics. The neoclassical growth theory based on the Solow growth model is mainly concerned with endogenous physical capital (Solow, 1956; Burmeister and Dobell, 1970; Azariadis 1993; and 
Barro and Sala-i-Martin, 1995). This study follows the traditional neoclassical growth theory in modelling economic production and physical capital accumulation. In Modelling behaviour of the household, we base on an alternative approach to determining behaviour of households proposed by Zhang (1993). In modelling human capital we follow Uzawa (1965) and Lucas (1988). Although economists have made great efforts in building growth models with endogenous human capital and physical capital with microeconomic foundations (Jones et al. 1993; Stokey and Rebelo, 1995; de la Croix and Licandro, 1999; Mino, 1996; Lagerlof, 2003; Alonso-Carrera and Freire-Sere, 2004; Galor, 2005; De Hek, 2005; and Sano and Tomoda, 2010), only a few studies deal with human and physical accumulation with endogenous population with microeconomic foundations within comprehensive analytical frameworks. The population change consists of dynamics of birth and death. Many factors may interact with changes in fertility (Barro and Becker, 1989; Galor and Weil, 1996; Doepke 2004; Adsera, 2005; Bosi and Seegmuller, 2012; Hock and Weil, 2012; and Chu et al. 2013). , the quality-quantity trade-off on children has been treated as a factor which affects the transition of economies from a stage of stagnation to perpetual growth. There are close relations between economic development and mortality rate (Schultz, 1993, 1998; Robinson and Srinivasan, 1997; Boucekkine et al., 2002; Blackburn and Cipriani, 2002; Chakraborty, 2004; Hazan and Zoabi, 2006; Fanti and Gori, 2011; Balestra and Dottori, 2012; Lancia and Prarolo, 2012). As explained in Zhang (2014), the model in this study is influenced by these researches on birth rate and mortality rate. The population dynamics is specially based on the Haavelmo (1954) population model and the Barro-Becker fertility choice model. The paper is organized as follows. Section 2 introduces the basic model with wealth accumulation and human capital accumulation. Section 3 simulates the model. Section 4 carries out comparative dynamic analysis with regard to oscillations in parameters. Section 5 concludes the study.

\section{The basic model}

The economy consists of one production sector and one education sector. Most aspects of the production sector are similar to the standard one-sector growth model. The economy produces only one (durable) good. We select the commodity to serve as numeraire. All the other prices being measured relative to the numeraire, households own assets of the economy and distribute their incomes to consumption, education, child bearing, and wealth accumulation. The production sectors or firms use physical capital and labour as inputs. Exchanges take place in perfectly competitive markets. Factor markets work well; factors are inelastically supplied and the available factors are fully utilized at every moment. Saving is undertaken only by households. All earnings of firms are distributed in the form of payments to the factors of production. We assume a homogenous population $N(t)$ at time. Let $T(t)$ and $T_{e}(t)$ represent for, respectively, the work time and study time of the representative household. The total work time is $T(t) N(t)$. We use $H(t)$ to stand for the level of human capital of the population. The total qualified labour force is 


$$
\bar{N}(t)=T(t) H^{m(t)}(t) N(t)
$$

where the parameter, $m(t)$, describes how effectively the population uses human capital in time $t$. The labour force is distributed between the two sectors. We assume that wage rates are identical between professions. The total capital stock of physical capital, $K(t)$, is allocated between the two sectors. We use subscripts $e$ and $i$ to stand for the education and industrial sector, respectively. We use $N_{j}(t)$ and $K_{j}(t)$ to stand for the labour force and capital stocks employed by sector $j$. The assumption of full employment of labour and capital implies

$$
K_{i}(t)+K_{e}(t)=K(t), \quad N_{i}(t)+N_{e}(t)=\bar{N}(t) .
$$

Equations (1) can be expressed as

$$
n_{i}(t) k_{i}(t)+n_{e}(t) k_{e}(t)=k(t), \quad n_{i}(t)+n_{e}(t)=1,
$$

in which

$$
k_{j}(t) \equiv \frac{K_{j}(t)}{N_{j}(t)}, \quad n_{j}(t) \equiv \frac{N_{j}(t)}{\bar{N}(t)}, k(t) \equiv \frac{K(t)}{\bar{N}(t)}, \quad j=i, e .
$$

\section{The industrial sector}

The production function is

$$
F_{i}(t)=A_{i} K_{i}^{\alpha_{i}}(t) N_{i}^{\beta_{i}}(t), \quad A_{i}(t), \alpha_{i}(t), \beta_{i}(t)>0, \alpha_{i}(t)+\beta_{i}(t)=1,
$$

where $A_{i}(t), \alpha_{i}(t)$, and $\beta_{i}(t)$ are positive parameters. The rate of interest, $r(t)$, and wage rate per unit work time (of the qualified labour), $w(t)$, are determined by markets. The marginal conditions for the industrial sector are

$$
r(t)+\delta_{k}(t)=\frac{\alpha_{i}(t) F_{i}(t)}{K_{i}(t)}=\alpha_{i}(t) A_{i}(t) k_{i}^{-\beta_{i}(t)}(t), \quad n(t)=\frac{\beta_{i}(t) F_{i}(t)}{N_{i}(t)}=\beta_{i}(t) A_{i}(t) k_{i}^{\alpha_{i}(t)}(t),(5)
$$

where $\delta_{k}(t)$ is the fixed depreciation rate of physical capital. 


\section{The education sector}

Following Zhang (2014), we consider the education sector perfect competition. Let $p(t)$ stand for the student's fee per unit in time. The production function of the education sector is a function of $K_{e}(t)$ and $N_{e}(t)$

$$
F_{e}(t)=A_{e}(t) K_{e}^{\alpha_{e}(t)}(t) N_{e}^{\beta_{e}(t)}(t), \quad \alpha_{e}(t), \beta_{e}(t)>0, \alpha_{e}(t)+\beta_{e}(t)=1,
$$

where $A_{e}(t), \alpha_{e}(t)$ and $\beta_{e}(t)$ are positive parameters. The marginal conditions are

$$
r(t)+\delta_{k}(t)=\alpha_{e}(t) A_{e}(t) p(t) k_{e}^{-\beta_{e}(t)}(t), w(t)=\beta_{e}(t) A_{e}(t) p(t) k_{e}^{\alpha_{e}(t)}(t) .
$$

The demand for and supply of education balances at any point in time

$$
T_{e}(t) N(t)=F_{e}(t)
$$

where $T_{e}(t) N(t)$ stand for the total education service.

\section{Human capital dynamics}

Following the Uzawa-Lucas model (Uzawa, 1965, Lucas, 1988) and Zhang (2014), we propose the following human capital dynamics

$$
\dot{H}(t)=\frac{v_{e}(t) F_{e}^{a_{e}(t)}(t)\left(H^{m(t)}(t) T_{e}(t) N(t)\right)^{b_{e}(t)}}{H^{\pi_{e}(t)}(t) N(t)}-\delta_{h}(t) H(t),
$$

where $\delta_{h}(t)(>0)$ is the depreciation rate of human capital, $v_{e}(t), a_{e}(t)$, and $b_{e}(t)$, are non-negative parameters. The sign of the parameter $\pi_{e}(t)$ is not specified as it may be either negative or positive. The term, $v_{e} F_{e}^{a_{e}}\left(H^{m} T_{e} N\right)^{b_{e}} / H^{\pi_{e}} N$, describes the contribution to human capital improvement through education. Human capital tends to increase with an increase in the level of education service, $F_{e}$, and in the (qualified) total study time, $H^{m} T_{e} N$.

\section{Consumer behaviours}

Consumers decide the time of education, consumption level of commodity, number of children, and amount of saving. We use an alternative approach to household proposed by Zhang (1993). Let per capita wealth be represented by $\bar{k}(t)$, where $\bar{k}(t) \equiv K(t) / N(t)$. By the definitions, we have

$$
\bar{k}(t)=k(t) T(t) H^{m(t)}(t) .
$$


Per capita current income from the interest payment and the wage payment is $y(t)=r(t) \bar{k}(t)+T(t) w(t)$.

The disposable income per head is given by

$$
\hat{y}(t)=y(t)+\bar{k}(t)
$$

Let $n(t)$ and $p_{n}(t)$ stand for the birth rate and the cost of birth at time. This study assumes that children will have the same level of wealth as that of the parent. The cost of the parent is

$$
p_{n}(t)=n(t) \bar{k}(t)
$$

Here, we neglect other costs such as time spent on children and purchases of goods and services (Becker, 1981; Barro and Becker, 1989; Wang et al. 1994; and Yip and Zhang, 1997). The household distributes the total available budget between saving, $s(t)$, consumption of goods, $c(t)$, education, $T_{e}(t)$, and bearing children, $n(t)$. The budget constraint is

$$
c(t)+s(t)+p(t) T_{e}(t)+\bar{k}(t) n(t)=(1+r(t)) \bar{k}(t)+T(t) w(t) .
$$

The consumer is faced with the following time constraint

$$
T(t)+T_{e}(t)=T_{0},
$$

where $T_{0}$ is the total available time for work and study. Insert (11) in (10)

$$
c(t)+s(t)+\bar{p}(t) T_{e}(t)+\bar{k}(t) n(t)=\bar{y}(t) \equiv(1+r(t)) \bar{k}(t)+T_{0} w(t),
$$

where $\bar{p}(t) \equiv p(t)+w(t)$ (which is the opportunity cost of education). As in Barro and Becker (1989), this study considers the parents' utility dependent on the number of children. The utility function is specified as follows

$$
U(t)=c^{\xi_{0}(t)}(t) s^{\lambda_{0}(t)}(t) T_{e}^{\eta_{0}(t)}(t) n^{v_{0}(t)}(t),
$$

where $\xi_{0}(t)$ is called the propensity to consume, $\lambda_{0}(t)$ the propensity to own wealth, $\eta_{0}(t)$ the propensity to receive education, and $v_{0}(t)$ the propensity to have children. The marginal conditions for maximizing $U(t)$ subject to (12) are 
where

$$
\begin{aligned}
& \xi(t) \equiv \rho(t) \xi_{0}(t), \lambda(t) \equiv \rho(t) \lambda_{0}(t), \quad \eta(t) \equiv \rho(t) \eta_{0}(t), \quad v(t) \equiv \rho(t) v_{0}(t), \\
& \rho(t)=\frac{1}{\xi_{0}(t)+\lambda_{0}(t)+\eta_{0}(t)+v_{0}(t)} .
\end{aligned}
$$

The birth and mortality rates and the population dynamics

The population dynamics is

$$
\dot{N}(t)=(n(t)-d(t)) N(t),
$$

where $n(t)$ and $d(t)$ are respectively the birth rate and mortality rate. It should be noted that Tournemaine and Luangaram (2012) consider mortality rate constant and specify the following technology of production of children: $n(t)=b T_{b}^{\theta}(t)$, where $T_{b}(t)$ is the time of rearing children and $b$ and $\theta$ are parameters. Equation (14) determines the birth rate as

$$
n(t)=\frac{v(t) \bar{y}(t)}{\bar{k}(t)}
$$

The mortality rate is taken on the following equation

$$
d(t)=\frac{\bar{v}(t)}{\bar{y}^{a(t)}(t) H^{b(t)}(t)},
$$

where $\bar{v}(t) \geq 0, \quad a(t) \geq 0$, and $b(t) \geq 0$. We call $\bar{v}(t)$ the mortality rate parameter. The equation implies that the mortality rate is negatively related to the disposable income and the level of human capital. From (16), (17) and (15) it is straightforward to get

$$
\dot{N}(t)=\left(\frac{v(t) \bar{y}(t)}{\bar{k}(t)}-\frac{\bar{v}(t)}{\bar{y}^{a(t)}(t) H^{b(t)}(t)}\right) N(t) .
$$




\section{Wealth dynamics}

According to the definition of $s(t)$, the change in the household's wealth is

$$
\dot{\bar{k}}(t)=s(t)-\bar{k}(t)
$$

We have thus built the dynamic model. The model is more robust than Zhang (2014) in that the parameters in this study are time-dependent. We now examine dynamics of the model.

\section{The dynamics and its properties}

Although the model contains dynamic interactions between population change, wealth accumulation and human capital dynamics, we now show that we use computer simulation to follow the motion of the dynamic system. Below we are providing a computational procedure to plot the motion of the economic system. We introduce a new variable

$$
z(t) \equiv \frac{r(t)+\delta_{k}}{w(t)}
$$

The following lemma shows that the dynamics can be expressed by the threedimensional differential equations system with $z(t), N(t)$, and $H(t)$ as the variables.

\section{Lemma}

The dynamics of the economic system is governed by the three dimensional differential equations

$$
\begin{aligned}
& \dot{z}(t)=\widetilde{\Omega}_{z}(z(t), N(t), H(t), t), \\
& \dot{N}(t)=\widetilde{\Omega}_{N}(z(t), N(t), H(t), t), \\
& \dot{H}(t)=\widetilde{\Omega}_{H}(z(t), N(t), H(t), t),
\end{aligned}
$$

where $\widetilde{\Omega}_{z}, \widetilde{\Omega}_{N}$, and $\widetilde{\Omega}_{H}$ are functions of $z(t), N(t), H(t)$, and $t$ defined in the Appendix. Moreover, all the other variables are determined as functions of $z(t)$, $N(t)$, and $H(t)$ at any point in time by the following procedure: $k_{i}(t)=\tilde{\alpha}_{i} / z(t)$ $\rightarrow \quad k_{e}(t)$ by (A2) $\rightarrow p(t)$ by (A3) $\rightarrow \quad r(t)$ and $w(t)$ by (5) $\rightarrow$ $\bar{p}(t)=p(t)+w(t) \rightarrow k(t)$ by (A12) $\rightarrow T(t)$ by (A7) $\rightarrow T_{e}(t)$ by (11) $\rightarrow \bar{y}(t)$ by $(\mathrm{A} 5) \rightarrow c(t), s(t)$, and $n(t)$ by (14) $\rightarrow n_{i}(t)$ and $n_{e}(t)$ by (A4) $\rightarrow \bar{N}(t)$ by (A1) 


$$
\begin{aligned}
& \rightarrow \quad N_{i}(t)=n_{i}(t) \bar{N}(t) \rightarrow N_{e}(t)=n_{e}(t) \bar{N}(t) \quad \rightarrow \quad K_{i}(t)=k_{i}(t) N_{i}(t) \quad \rightarrow \\
& K_{e}(t)=k_{e}(t) N_{e}(t) \rightarrow F_{i}(t) \text { by }(4) \rightarrow F_{e}(t) \text { by }(6) .
\end{aligned}
$$

As the expressions are too complicated, we simulate the model to illustrate the behaviour of the system. In the reminder of this section we summarize the simulation results in Zhang (2014) when all the parameters are time-independent. The next section simulates the motion when the parameters are exogenously oscillatory. We specify $\delta_{k}=0.05, \delta_{h}=0.05$, and $T_{0}=1$. The requirement $T_{0}=1$ will not affect our analysis. The depreciation rate of physical capital is often fixed around 0.05 in economic studies. As shown by Stokey and Rebelo (1995), the depreciation rate of human capital is reasonably valued within a range between 0.03 and 0.08 for the US economy. The other parameter values are taken on

$\alpha_{i}=0.35, \quad \alpha_{e}=0.45, \lambda_{0}=0.7, \quad \xi_{0}=0.08, \eta_{0}=0.01 \quad v_{0}=0.2, A_{i}=1.2, A_{e}=1.2$, $m=0.8, v_{e}=1.3, a_{e}=0.2, b_{e}=0.1, \pi_{e}=-0.1 \quad a=0.3 \quad b=0.1, \bar{v}=0.6$.

The propensity to save is 0.7 and the propensity to receive education is 0.01 . The propensity to consume goods is 0.08 . The technological parameters of the two sectors are specified at $A_{i}=A_{e}=1.2$. The conditions $\pi_{e}=-0.1$ means that the learning by education exhibits decreasing effects in human capital. The human capital utilization efficiency is 0.8 . The initial conditions are specified as

$$
z(0)=0.3, \quad N(0)=2.7, \quad H(0)=4 .
$$

The simulation result is plotted in Figure 1.
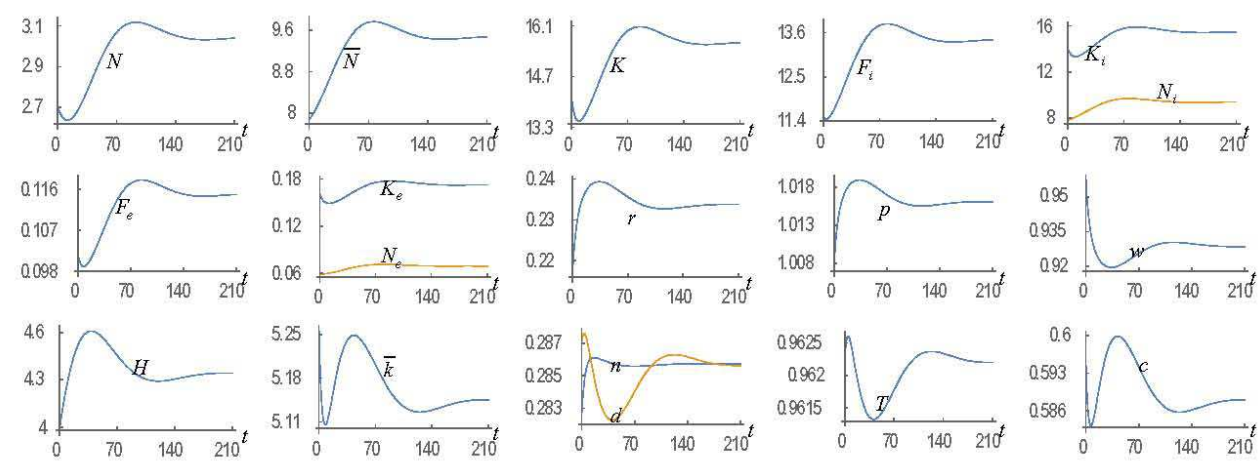

Figure 1. The Motion of the Economic System 
We observe that the variables tend to become stationary over time. The simulation demonstrates that the dynamic system has a unique equilibrium point. The equilibrium values of the variables are

$N=3.04, \quad H=4.34, \quad K=15.65, \quad \bar{N}=9.47, \quad N_{i}=9.40, \quad N_{e}=0.067$,

$K_{i}=15.48, K_{e}=0.17, k_{i}=1.65, k_{e}=2.50, F_{i}=13.43, F_{e}=0.12, n=d=0.286$,

$k=1.65, \quad r=0.234, \quad p=1.02, w=0.93, \bar{k}=5.14, T=0.96, \quad c=0.59$.

We calculate the three eigenvalues: $-0.21,-0.08$, and -0.04 . As the three eigenvalues are real and negative, the unique equilibrium is locally stable. Hence, the system always approaches its equilibrium if it is not far from the equilibrium.

\section{Comparative dynamic analysis in some parameters by simulation}

Zhang (2014) shows how the system reacts to a once-for-all change in parameters. This section shows how the system reacts to time-dependent changes in parameters. For convenience we consider the parameters in (21) as the long-term average values. We make small perturbations around these long-term values. In this study we use $\bar{\Delta} x_{j}(t)$ to stand for the change rate of the variable $x_{j}(t)$ due to changes in a parameter value.

\section{Oscillations in the mortality rate parameter}

We now examine the case that the mortality rate parameter is oscillated as follows

$$
\bar{v}(t)=0.6+0.04 \sin (t)
$$

The simulation results are plotted in Figure 2. The oscillations in the mortality rate parameter causes fluctuations in the death rate and have little impact on the birth rate. The population, total labour force and the total physical capital fluctuate. The output levels of the two sectors and the levels of two inputs of the two sectors are oscillatory with small amplitudes. We see that the rate of interest, wage rate, human capital, wealth, work time and consumption are also oscillatory with negligible amplitudes. 

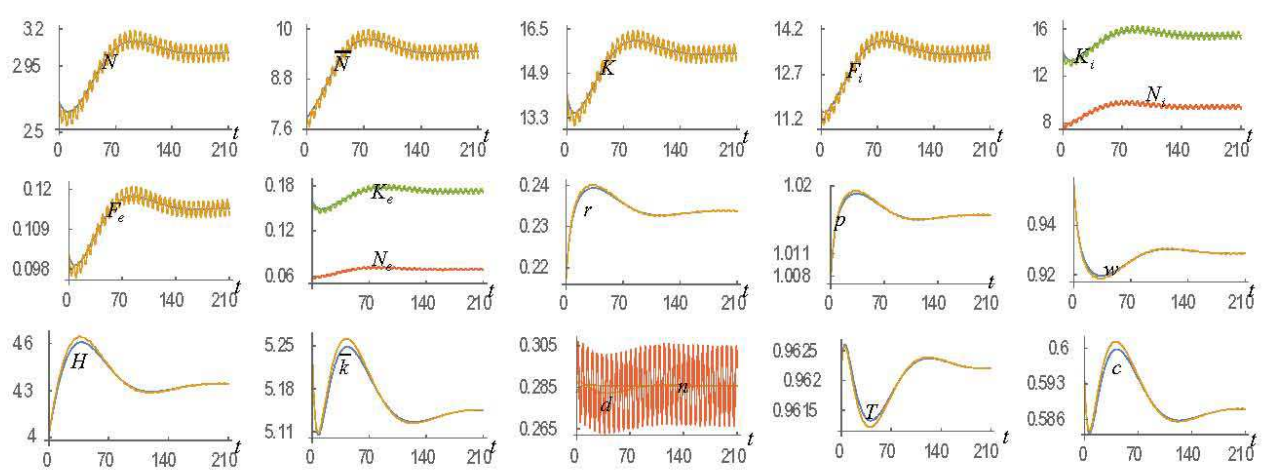

Figure 2. Oscillations in the Mortality Rate Parameter

\section{Oscillations in the output elasticity of the industrial sector's capital input}

We now study what happens in the economy if the output elasticity of the industrial sector's capital input experiences the following fluctuations

$$
\alpha_{i}(t)=0.35+0.01 \sin (t) \text {. }
$$

Different from the effects caused by oscillations in the mortality rate parameter, the oscillations in the output elasticity causes fluctuations in the rate of the interest, the price of education, wage rate, wealth, distribution, and consumption level. The population, total labour force, the total physical capital, and the two sectors' output and input levels fluctuate with negligible amplitudes.
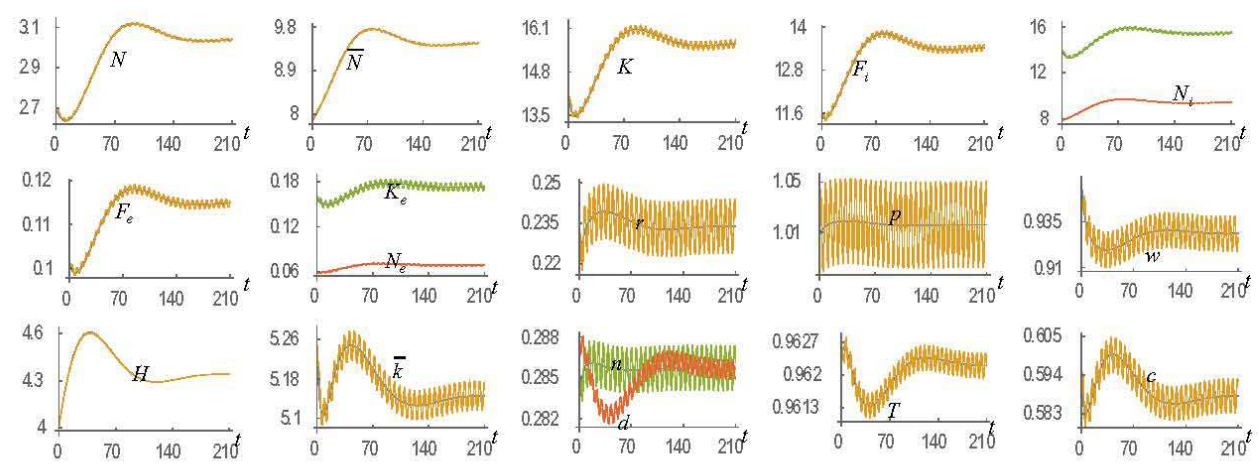

Figure 3. Oscillations in the Output Elasticity of the Industrial Sector's Capital Input 


\section{Oscillations in the propensity to save}

We now study the impact of the following fluctuations in the propensity to save

$$
\lambda_{0}(t)=0.7+0.02 \sin (t) \text {. }
$$

All the variables fluctuate around their long-term trends. Both human capital and wealth fluctuate with negligible amplitudes.
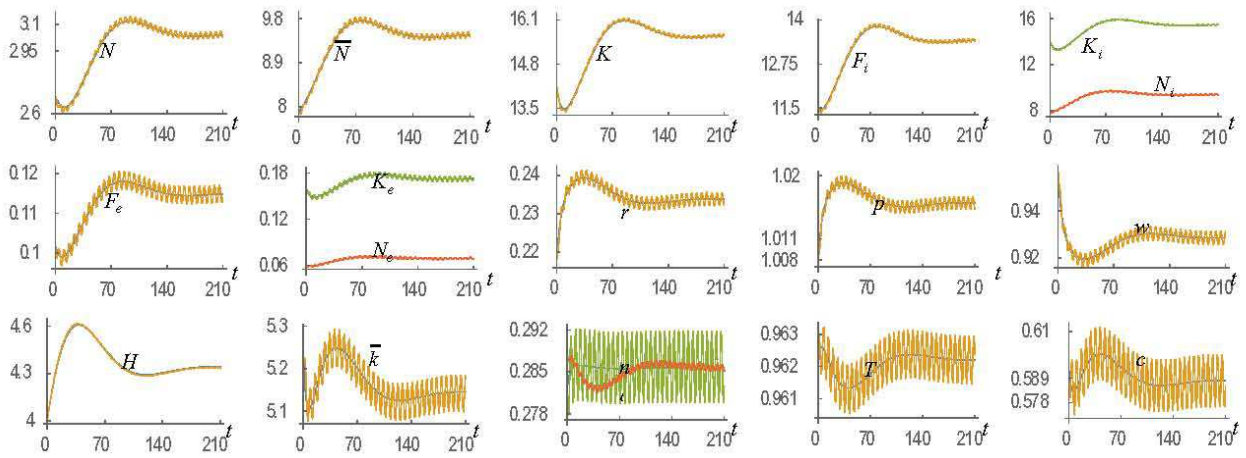

Figure 4. Oscillations in the Propensity to Save

\section{Oscillations in the mortality rate elasticity because of disposable income}

We now examine how strongly the disposable income may affect population growth. We consider the following fluctuations in the mortality rate elasticity because of disposable income

$$
a(t)=0.3+0.02 \sin (t) .
$$

The effects on the economic system are similar to the effects caused by oscillations in the mortality rate parameter. The death rate experiences fluctuations and the impact on the birth rate is negligible. The population, total labour force and the total physical capital fluctuate. The output levels of the two sectors and the levels of two inputs of the two sectors are oscillatory with small amplitudes. We see that the rate of interest, wage rate, human capital, wealth, work time and consumption are also oscillatory with negligible amplitudes. 

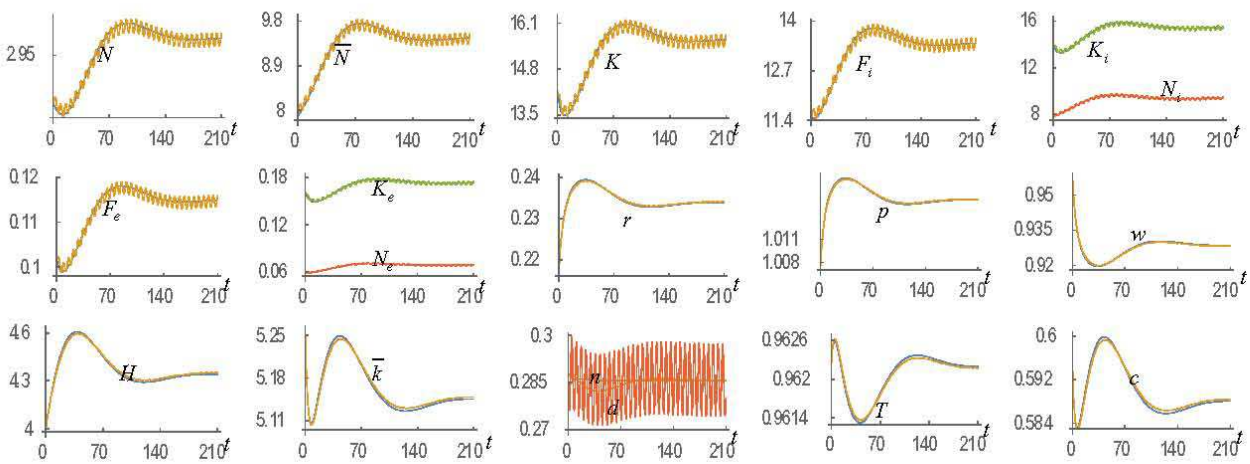

Figure 5. Oscillations in the Mortality Rate Elasticity because of Disposable Income

\section{Oscillations in the propensity to receive education}

We consider the following fluctuations in the propensity to receive education

$$
\eta_{0}(t)=0.01+0.002 \sin (t)
$$

The fluctuations in the propensity to receive education cause oscillations in the time distribution. The birth rate is largely oscillated. The education sector's output and two inputs experience oscillations with large amplitudes. The amplitude of the oscillations in the death rate is negligible. The population, total labour force and the total physical capital fluctuate with small amplitudes. We see that the rate of interest, wage rate, human capital, wealth, and consumption are also oscillatory with small amplitudes.
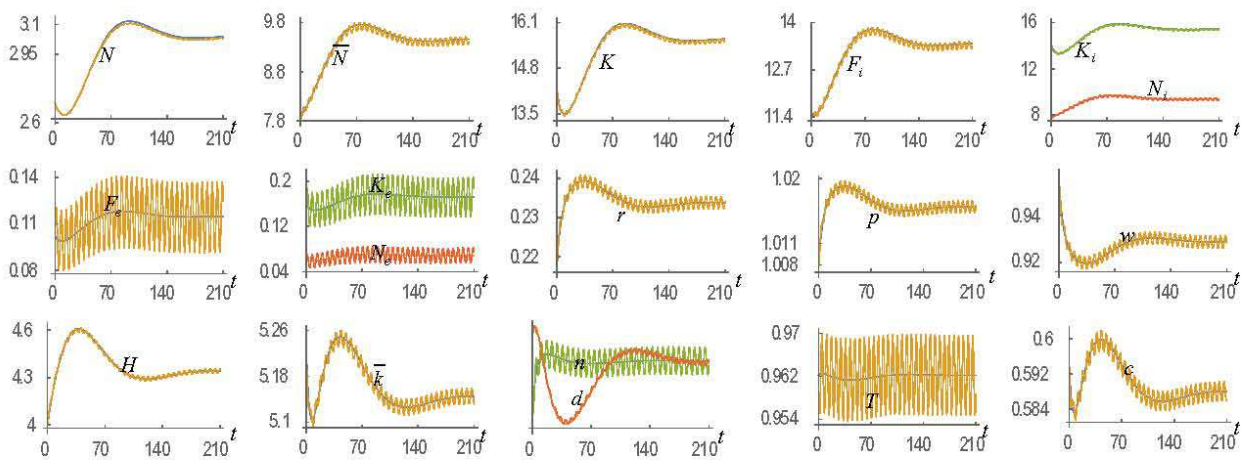

Figure 6. Oscillations in the Propensity to Receive Education 


\section{Concluding Remarks}

This paper was concerned with existence of business oscillations in the economic growth model with endogenous population growth and physical and human capital accumulation proposed by Zhang (2014). This study generalized Zhang's model by treating all the time-independent parameters as time-dependent parameters. The model is a synthesis of the Solow growth model, Uzawa-Lucas two-sector model, and the Haavelmo population model and the Barro-Becker fertility choice model. The model studies the dynamic interdependence between population change, wealth accumulation, and human capital accumulation. We simulated the model to demonstrate existence of business cycles under different periodic shocks.

\section{Appendix: Proving the Lemma}

We now confirm the lemma. In the appendix we omit time in expressions when there is no confusion. By (5) and (7), we obtain

$$
z \equiv \frac{r+\delta_{k}}{w}=\frac{\tilde{\alpha}_{i}}{k_{i}}=\frac{\tilde{\alpha}_{e}}{k_{e}},
$$

where $\tilde{\alpha}_{j} \equiv \alpha_{j} / \beta_{j}$. From (A1) we have

$$
k_{e}=\alpha k_{i},
$$

where $\alpha \equiv \alpha_{e} \beta_{i} / \alpha_{i} \beta_{e}$ ( $\neq 1$ assumed). From (5), we determine $r$ and $w$ as functions of $k_{i}$. From (A2), (5) and (7), we obtain

$$
p=\beta_{0} k_{i}^{\beta},
$$

where

$$
\beta_{0} \equiv \frac{\alpha^{\beta_{e}} \alpha_{i} A_{i}}{\alpha_{e} A_{e}}, \quad \beta \equiv \beta_{e}-\beta_{i}
$$

We determine $p$ as a function of $k_{i}$. As $k_{i}=\tilde{\alpha}_{i} / z$, we determine $k_{i}, k_{e}$, $p, r, w$, and $\bar{p}$ as functions of $z$.

From (A1) and (1), we solve the labour distribution as functions of $k_{i}$ and $k$

$$
n_{i}=\frac{\alpha k_{i}-k}{\bar{\alpha} k_{i}}, n_{e}=\frac{k-k_{i}}{\bar{\alpha} k_{i}},
$$


where $\bar{\alpha} \equiv \alpha-1$. Insert (2) and $\bar{k}=k T H^{m}$ in the definition of $\bar{y}$ in (12)

$$
\bar{y}=(1+r) k T H^{m}+T_{0} w .
$$

From $\bar{p} T_{e}=\eta \bar{y}$ in (14) and (A5), we have

$$
\bar{p} T_{e}=(1+r) \eta k T H^{m}+\eta T_{0} w .
$$

From (11) and (A6), we have

$$
T=\frac{(\bar{p}-\eta w) T_{0}}{(1+r) \eta k H^{m}+\bar{p}} .
$$

Insert (A7) in (1)

$$
\bar{N}(k, z, N, H)=\frac{(\bar{p}-\eta w) H^{m} N T_{0}}{(1+r) \eta k H^{m}+\bar{p}} .
$$

From (8) and (6), we have

$$
T_{e}=A_{e} T n_{e} H^{m} k_{e}^{\alpha_{e}} .
$$

From (A9) and (11), we have

$$
T=\frac{T_{0}}{1+A_{e} n_{e} H^{m} k_{e}^{\alpha_{e}}} .
$$

From (A7) and (A10), we solve

$$
n_{e}=\left(\frac{(1+r) \eta k H^{m}+\bar{p}}{\bar{p}-\eta w}-1\right) \frac{1}{A_{e} H^{m} k_{e}^{\alpha_{e}}} .
$$

From (A4) and (A11), we solve

$$
k(z, N, H, t)=\left(\frac{A_{e} H^{m} k_{e}^{\alpha_{e}}}{\bar{\alpha}}+\frac{\eta w}{\bar{p}-\eta w}\right)\left[\frac{A_{e} k_{e}^{\alpha_{e}}}{\bar{\alpha} k_{i}}-\frac{(1+r) \eta}{\bar{p}-\eta w}\right]^{-1} H^{-m}
$$


We determine all the variables as functions of $z(t), N(t), H(t)$, and $t$ at any point in time by the following procedure: $k_{i}=\tilde{\alpha}_{i} / z$ by (A1) $\rightarrow k_{e}$ by (A2) $\rightarrow$ $p$ by (A3) $\rightarrow r$ and $w$ by (5) $\rightarrow \bar{p}=p+w \rightarrow k$ by (A12) $\rightarrow T$ by (A7) $\rightarrow$ $T_{e}$ by (11) $\rightarrow \bar{y}$ by (A5) $\rightarrow c, s$, and $n$ by (14) $\rightarrow n_{i}$ and $n_{e}$ by (A4) $\rightarrow \bar{N}$ by (A1) $\rightarrow N_{i}=n_{i} \bar{N} \rightarrow N_{e}=n_{e} \bar{N} \rightarrow K_{i}=k_{i} N_{i} \rightarrow K_{e}=k_{e} N_{e} \rightarrow F_{i}$ by (4) $\rightarrow$ $F_{e}$ by (6).

From this procedure, (9) and (18), it is straightforward to show that the motion of human capital and the population can be expressed as function of $z(t)$, $N(t), H(t)$, and $t$ at any point in time

$$
\begin{aligned}
& \dot{H}=\widetilde{\Omega}_{H}(z, N, H, t), \\
& \dot{N}=\tilde{\Omega}_{N}(z, N, H, t) .
\end{aligned}
$$

We now show that change in $z(t)$ can also be expressed as a differential equation in terms of $z(t), N(t), H(t)$, and $t$. From (19), we have

$$
\dot{\bar{k}}=\Omega_{0}(z, N, H, t) \equiv \lambda \bar{y}-\bar{k}
$$

Taking derivatives of $\bar{k}=k T H^{m}$ with respect to time, we have

$$
\frac{\dot{\bar{k}}}{\bar{k}}=\frac{1}{k} \frac{\partial k}{\partial t}+\frac{1}{T} \frac{\partial T}{\partial t}+\left(\frac{1}{k} \frac{\partial k}{\partial z}+\frac{1}{T} \frac{\partial T}{\partial z}\right) \dot{z}+\left(\frac{1}{k} \frac{\partial k}{\partial N}+\frac{1}{T} \frac{\partial T}{\partial N}\right) \widetilde{\Omega}_{N}+\left(\frac{1}{k} \frac{\partial k}{\partial H}+\frac{1}{T} \frac{\partial T}{\partial H}+\frac{m}{H}\right) \widetilde{\Omega}_{H},
$$

where we also use (A13). From (A14) and (A15), we solve

$$
\begin{aligned}
& \dot{z}=\widetilde{\Omega}_{z}(z, N, H . t) \equiv\left(\frac{1}{k} \frac{\partial k}{\partial z}+\frac{1}{T} \frac{\partial T}{\partial z}\right)^{-1} \\
& {\left[\frac{\Omega_{0}}{\bar{k}}-\frac{1}{k} \frac{\partial k}{\partial t}-\frac{1}{T} \frac{\partial T}{\partial t}-\left(\frac{1}{k} \frac{\partial k}{\partial N}+\frac{1}{T} \frac{\partial T}{\partial N}\right) \widetilde{\Omega}_{N}-\left(\frac{1}{k} \frac{\partial k}{\partial H}+\frac{1}{T} \frac{\partial T}{\partial H}+\frac{m}{H}\right) \widetilde{\Omega}_{H}\right]}
\end{aligned}
$$


The three differential equations (A13) and (A16) contain three variables $z(t), N(t)$, and $H(t)$. We thus proved the lemma.

\section{References}

Adsera, A. (2005) Vanishing Children: From High Unemployment to Low Fertility in Developed Countries. American Economic Review 95, 189-93.

Alonso-Carrera, J. and Freire-Sere, M.J. (2004) Multiple Equilibria, Fiscal Policy and Human Capital Accumulation. Journal of Economic Dynamics and Control 28, 841-56.

Azariadis, C. (1993) Intertemporal Macroeconomics. Oxford: Blackwell.

Balestra, C. and Dottori, D. (2012) Aging Society, Health and the Environment. Journal of Population Economics 25, 1045-76.

Barro, R.J. and Becker, G.S. (1989) Fertility Choice in a Model of Economic Growth. Econometrica 57, 481-501.

Barro, R.J. and X. Sala-i-Martin (1995) Economic Growth. New York: McGraw-Hill, Inc.

Becker, G. S. (1981) A Treatise on the Family. Cambridge, MA.: Harvard University Press.

Blackburn, K. and Cipriani, G.P. (2005) A Model of Longevity, Fertility and Growth. Journal of Economic Dynamics \& Control 26, 187-204.

Bosi, S. and Seegmuller, T. (2012) Mortality Differential and Growth: What Do We Learn from the Barro-Becker Model? Mathematical Population Studies 19, $27-50$.

Boucekkine, R., de la Croix, D. and Licandro, O. (2002) Vintage Human Capital. Demographic Trends, and Endogenous Growth. Journal of Economic Growth 104, $340-75$.

Burmeister, E. and Dobell, A.R. (1970) Mathematical Theories of Economic Growth. London: Collier Macmillan Publishers.

Chakraborty, B. and Gupta, M.R. (2009) Human Capital, Inequality, Endogenous Growth and Education Subsidy: A Theoretical Analysis. Research in Economics 63, 77-90.

Chatterjee, B. S. and Ravikumar, B. (1992) A Neoclassical Model of Seasonal Fluctuations. Journal of Monetary Economics 29 (1), 59-86.

Chu, A.C., Cozzi, G. and Liao, C.H. (2013) Endogenous Fertility and Human Capital in a Schumpeterian Growth Model. Journal of Population Economics 26, 181-202.

De Hek, P.A. (2005) On Taxation in a Two-Sector Endogenous Growth Model with Endogenous Labor Supply. Journal of Economic Dynamics and Control 30, 655-85.

De la Croix, D. and Licandro, O. (1999) Life Expectancy and Endogenous Growth. Economics Letters 65, 255-63.

Doepke, M. (2004) Accounting for Fertility Decline During the Transition to Growth. Journal of Economic Growth 9, 347-83.

Fanti, L. and Gori, L. (2011) Public Health Spending, Old-Age Productivity and Economic Growth: Chaotic Cycles under Perfect Foresight. Journal of Economic Behavior \& Organization 78, 137-51.

Gabaix, X. (2011) The Granular Origins of Aggregate Fluctuations. Econometrica 79, $733-72$.

Galor, O. (2005) From Stagnation to Growth: Unified Growth Theory, in Handbook of Economic Growth, edited by Aghion, P. and Durlauf, S.N. Amsterdam: North Holland.

Galor, O. and Weil, D.N. (1996) The Gender Gap, Fertility, and Growth. American Economic Review 86, 374-87.

Giovanni, J. Di., Levchenko, A., and Mejean, I. (2014) Firms, Destinations, and Aggregate Fluctuations. Econometrica 82 (4), 1303-40. 
Haavelmo, T. (1954) A Study in the Theory of Economic Evolution. North-Holland: Amsterdam.

Hazan, M. and Zoabi, H. (2006) Does Longevity Cause Growth? A Theoretical Critique. Journal of Economic Growth 11, 363-76.

Hock, H. and Weil, D.N. (2012) On the Dynamics of the Age Structure, Dependency, and Consumption. Journal of Population Economics 25, 1019-43.

Jones, L.E., Manuelli, R.E., and Rossi, P.E. (1993) Optimal Taxation in Models of Endogenous Growth. Journal of Political Economy 101, 485-517.

Lagerlof, N.P. (2003) From Malthus to Modern Growth: The Three Regimes Revisited. International Review of Economics 44, 755-77.

Lancia, F. and Prarolo, G. (2012) A Politico-Economic Model of Aging, Technology Adoption and Growth. Journal of Population Economics 25, 989-1018.

Lucas, R.E. (1977) Understanding Business Cycles. Carnegie-Rochester Conference Series on Public Policy 5, 7-29.

Lucas, R.E. (1988) On the Mechanics of Economic Development. Journal of Monetary Economics 22, 3-42.

Ludwig, A. and Vogel, E. (2009) Mortality, Fertility, Education and Capital Accumulation in a Simple OLG Economy. Journal of Population Economics 23, 703-35.

Mino, K. (1996) Analysis of a Two-Sector Model of Endogenous Growth with Capital Income Taxation. International Economic Review 37, 227-51.

Robinson, J.A. and Srinivasan, T.N. (1997) Long-term Consequence of Population Growth: Technological Change, Natural Resources, and the Environment, in Handbook of Population and Family Economics, edited by Rozenzweig, M.R. and Stark, O. Amsterdam: North-Holland.

Sano, K. and Tomoda, Y. (2010) Optimal Public Education Policy in a Two Sector Model. Economic Modelling 27, 991-95.

Schultz, P.T. (1993) Mortality Decline in the Low-Income World: Causes and Consequences. American Economic Review 83, 337-42.

Schultz, P.T. (1998) Health and Schooling Investments in Africa. The Journal of Economic Perspectives 13, 67-88.

Solow, R. (1956) A Contribution to the Theory of Growth. Quarterly Journal of Economics 70, 65-94.

Stella, A. (2015) Firm Dynamics and the Origins of Aggregate Fluctuations. Journal of Economic Dynamics and Control (forthcoming). Lucas, R.E. (1988) On the Mechanics of Economic Development. Journal of Monetary Economics 22, 3-42.

Stokey, N.L. and Rebelo, S. (1995) Growth Effects of Flat-Rate Taxes. Journal of Political Economy 103, 519-50.

Tournemaine, F. and Luangaram, P. (2012) R\&D, Human Capital, Fertility, and Growth. Journal of Population Economics 25, 923-53.

Uzawa, H. (1965) Optimal Technical Change in an Aggregative Model of Economic Growth. International Economic Review 6, 18-31.

Wang, P., Yip, C.K. and Scotese, C.A. (1994) Fertility Choice and Economic Growth: Theory and Evidence. Review of Economics and Statistics 71, 255-66.

Yip, C. and Zhang, J. (1997) A Simple Endogenous Growth Model with Endogenous Fertility: Indeterminacy and Uniqueness. Journal of Population Economics 10, 97-100.

Zhang, W.B. (1993) Woman's Labor Participation and Economic Growth - Creativity, Knowledge Utilization and Family Preference. Economics Letters 42, 105-110.

Zhang, W.B. (1991) Synergetic Economics. Springer-Verlag, Heidelberg. 
Zhang, W.B. (2005) Differential Equations, Bifurcations, and Chaos in Economics. Singapore: World Scientific.

Zhang, W.B. (2006) Discrete Dynamical Systems, Bifurcations and Chaos in Economics. Elsevier: Amsterdam.

Zhang, W.B. (2014) Endogenous Population with Human and Physical Capital Accumulation. International Review of Economics 61(3), 231-52. 